\section{OLD WORLD}

\section{WATER RESOURCES}

\section{All Quiet af the Wash}

WATeR storage schemes in the Wash, which are now being studied in detail, could eventually yield about 600 million gallons of water a day to help meet the expected doubling in the demand for water by 2000 . Decisions will be taken in 1974 on whether or not to build the first stage of the scheme which could yield 100 million gallons a day by 1983-4. These were two of the facts underlined by the Water Resources Board at a public meeting held in King's Lynn last week to discuss the proposals. The board was there in force, not merely to provide information but also to answer particular questions about the scheme.

The scheme is the result of a desk study published in 1970 which stated that with the present levels of technology it would not be possible to build a full barrage across the mouth of the Wash. It did, however, recommend that the building of four reservoirs in the Wash be studied in full. Under the proposals four bunded reservoirs would be built in stages to meet demand as and when it arose. The feasibility study will decide if the reservoirs can be built and if the benefits they bring will outweigh the disadvantages.

The possible advantages, apart from a large supply of potable water, are that valleys and agricultural land elsewhere would be saved from flooding as reservoirs, considerable recreational facilities could become available, some land could be reclaimed from the sea, and new freshwater habitats for flora and fauna would be created. The possible disadvantages are that some saltwater habitats would be lost, local fisheries will be affected, and the effects of the scheme on land drainage will have to be carefully considered.

Research into various aspects of the scheme is being undertaken by the Hydraulics Research Station, the Natural Environment Research Council and the East Anglia Economic Planning Board, all of whom were at the meeting to answer questions. The consulting engineers on the scheme, Binnie and Partners, were also represented by $\mathrm{Mr} \mathrm{T}$. G. Hammond, who explained that in the next year a trial embankment will be built at a cost of f1 million to study the best means of building the reservoir walls, and that later a second wall will be built off-shore for further studies, before the decision to go ahead is taken. Assurances were given at the meeting that all the tidal and siltation aspects of the schemes are being carefully studied, and that the effects of the scheme on the local fisheries will also be taken into account. The meeting was surprisingly uneventful, with the audience taking the board's assurances without question; indeed many of the people packed into the Guildhall of St George seemed in favour of the scheme going ahead. Assurances were also given that the visual aspects of the scheme would be carefully studied and that the building of the scheme in stages-with the smallest of the reservoirs being built first-would allow the full effects of the scheme to be predicted before it was all irrevocably completed.

The total cost of the study will be in the order of $£ 2.5$ million and will establish the feasibility and desirability of all stages of the scheme. It is unlikely, however, unless demands for water rise faster than expected, that more than one of the four reservoirs will be built this century.

On the evidence of the public meeting it would appear that the Water Resources Board's proposals for the Wash are likely to go through much more quietly than the proposals for the scheme at Morecambe Bay, which have met with severe opposition in some quarters. The full feasibility study for Morecambe Bay, which was commissioned in 1966, has now been completed and is due for publication at the end of this month.

\section{SCIENCE POLICY}

\section{Royal Society Puis Case}

IT is unusual for the president of the Royal Society to give evidence before a select committee of the House of Commons but, for the scientific community in Britain, these are unusual times. It was with this background that Sir Alan Hodgkin appeared before the Science and Technology Select Committee last week to give the Royal Society's views on the proposed reorganization.

Sir Alan expressed the Royal Society's opposition to Lord Rothschild's proposals for reforming research and development in Britain on the grounds that Rothschild's report was a "misleading oversimplification which does not provide a satisfactory framework for government research and development". Sir Alan therefore placed the Royal Society behind Sir Frederick Dainton and the Council for Scientific Policy in opposition to Lord Rothschild.

In a memorandum produced for the benefit of the Select Committee-the habit seems to be contagious - the Royal Society questions the wisdom of having had an enquiry into such an all embracing subject carried out by one scientist. The Royal Society considers that an "impression is conveyed that the report had to be prepared in haste with little opportunity for consulting the scientific community". Sir Alan in evidence amplified this theme by saying that he did not think that "working lunches and conversations in pubs" constituted sufficient consultation when such far reaching and important changes were being considered. Sir Alan thought that a much better way of studying proposed changes would have been to set up an enquiry such as was done under Sir Burke Trend in the early 1960s where the processes of decision making were more open.

In one respect Sir Alan disagreed with Sir Frederick Dainton's report. Sir Alan told the Select Committee that he did not think that the Board of the Research Councils, if set up as recommended by the Council for Scientific Policy, should have the executive members of the research councils as members. This, however, did not imply that the Royal Society is in favour of setting up the board and the society reserves judgment on this until the future of the research councils is known.

Sir Alan admitted that Lord Rothschild had taken no apparent heed of a memorandum on the future of the research councils sent to him by the Royal Society in July 1971. This memorandum, which expressed contrasting views to those put forward by Lord Rothschild, has apparently suffered the same fate as the advice given by Sir Frederick Dainton to Lord Rothschild last summer before the green paper was published.

The Royal Society in its memorandum stresses, as did Sir Alan in evidence, that the prime factor in determining the allocation of funds for science should be the welfare of the nation, and that "responsibility and accountability should be clearly defined and allocated". Sir Alan, like Sir Frederick Dainton two weeks ago, felt that the research councils were accountable for their programmes because they produced comprehensive annual reports. Sir Alan also considered that the research councils were more accountable for their research than government departments by virtue of the reports they produced - thus throwing a new light on the problem of accountability.

While considering that the Rothschild enquiry has not been "an adequate basis for change" the Royal Society also feels that the time is not apt for a new enquiry. It does, however, recommend interim action for the government to consider, which is very similar to that suggested by the Council for Scientific Policy. The basis of the proposal is that there should be a partnership between the user ministries and the research councils in running applied research programmes. The amount of 